\title{
СОЦИАЛЬНЫЙ ЦИРК В ПОСТСОЦИАЛИСТИЧЕСКОЙ РОССИИ: КЕЙС-СТАДИ НОВОЙ СОЛИДАРНОСТИ
}

\begin{abstract}
В статье на основании результатов изучения российской общественной организации, созданной в начале $2000-$ х гг., ориентированной на развитие потенциала детей и подростков из групп социального риска (с уличным опытом, из бедных семей), анализируется, каким образом происходит их включение в общество, как с помощью цирковых методов и социально ориентированного активизма удается решать проблемы исключения и воспроизводства бедности. Рассматриваются смыслы, приписываемые социальному цирку участниками, сотрудниками и сторонниками; раскрываются стратегии включения групп разных социальных классов в цирк и как эти стратегии поддерживаются в процессе взаимодействия с внешними сторонами (гражданскими активистами, местным сообществом, чиновниками и спонсорами). Таким образом реконструируется концепция включения, представленная как процесс разворачивания потенциала, когда с реализацией внешних возможностей происходит накопление внутренних ресурсов, а также усиливается способность действовать и производить позитивный эффект. Авторы показывают, что включение социально-уязвимых групп может менять структуры возможностей на практике при наличии трех условий. Во-первых, через изменение статуса - когда негативная идентификация не только переворачивается по смыслу, но и формирует платформу для практического продвижения особого статуса и различий участников, с учетом их интересов. Во-вторых, установка на достижение усиливает позиции участников, если она сочетается с формированием социальных навыков по их согласованию. В-третьих, возможности аккумулируются, если
\end{abstract}

Светлана Ярошенко - к.с.н., доцент, кафедра сравнительной социологии, СанктПетербургский государственный университет, Санкт-Петербург, Россия. Электронная почта: s.yaroshenko@ spbu.ru.

Астрид Шорн- аспирантка, Свободный университет, Берлин, Германия. Электронная почта: astrid.schorn@fu-berlin.de. 
закрепляются в эмансипационных способах взаимодействия на индивидуальном, групповом и локальном уровнях, предполагающих осознание причин угнетения, продвижение интересов уязвимых групп, приращение их опыта и расширение социальных связей. В заключение рассматривается рефлексивная солидарность, предполагающая совместную выработку моральных ориентиров и вариативность их реализации.

Ключевые слова: социальный цирк, кейс-стади, режим включения, управляющие отношения, социологический марксизм, постсоциализм

DOI: 10.17323/727-0634-2020-18-3-491-508

Глобализация рыночных отношений отразилась на росте социального неравенства и исключения. На новом витке общественного развития остро стоит вопрос «что делать» и как менять капиталистическую систему: через политику распределения или признания (Fraser, Honneth 2003), с помощью педагогики угнетенных (Freire, Ramos [1970] 2009), «реальных утопий» (Wright 2012), управляемого включения (World Bank 2013) или общественных движений (Paret et al. 2017). Социологи все чаще критикуют способность существующих стратегий сдерживать распространение исключающей политики и обеспечивать маргиналам как пересечение границ, сужающих возможности восходящей мобильности, так и равное включение в рыночную экономику (Лыткина 2012; Burawoy 2015; Kerner 2017).

Ключевой остается проблема учета специфических потребностей без усиления экономического неравенства или изоляции в обществе. Несмотря на разные подходы к ее решению необходимость защиты гражданского общества от избыточного давления рынков и государств по-прежнему актуальна. В этом свете значение приобретают общественные образования или новые формы солидарности, артикулирующие различия и формирующие общий интерес, предлагающие коллективные решения актуальных социальных вопросов и ориентированные на улучшение мира с учетом маргинальности. В фокусе нашего внимания- основания и рамки для применения и развития таких эмансипационных проектов, представляющих альтернативу доминирующим институтам и социальным структурам в бывшей социалистической стране, на примере социального цирка.

\section{Социальный цирк в качестве изучаемого случая}

Социальный цирк в Санкт-Петербурге создан в 2000 г. как инициативный проект, в котором с помощью цирковой педагогики организуется работа с детьми и подростками из групп риска. За это время состоялось четыре набора, с общей численностью выпускников, прошедших школу цирка (минимум три года), около 40 человек. До выпуска доходит лишь треть участников. В настоящее время в цирке занимается около 70 человек. 
Детей набирают в кризисных центрах и коррекционных школах, иногда их направляют социальные службы и общественные организации. В некоторых случаях инициативу проявляют родители или родственники. Цирк ориентирован на тех детей и подростков, которые испытывают разные виды неблагополучия (бедность, сложные отношения в семьях, учеба в коррекционной школе, судимость). Так, среди опрошенных нами участников цирка, половина - из семей рабочих, треть- из семей специалистов и служащих, около четверти- из семей неработающих по разным причинам. Дети из семей с более высоким экономическим положением живут в ситуации нестабильных семейных отношений. Шестая часть участников состоит на учете в комиссии по делам несовершеннолетних.

Основная задача данной общественной организации- изменить статус социально-уязвимой группы детей и подростков, чьи возможности для самореализации и признания в обществе ограничены не только низкими родительскими ресурсами, но и существующими по отношению к ним предубеждениями и ошибочными представлениями о причинах неблагополучия и видах необходимой поддержки. Педагогическая концепция работы основана на доступности занятий (они бесплатны для целевой группы), на их регулярности и направленности на результат (создание спектакля), на талантах детей, а не их проблемах (нет специального отбора, в идеале для каждого находится роль в спектаклях, дети из сложных семей представляются с положительной стороны), со стремлением наладить с участниками партнерские отношения и создать на базе цирка дружественное пространство.

В настоящий момент основными спонсорами являются петербургские предприниматели, около трети расходов цирк покрывает самостоятельно через платные программы. В штате занято около восьми постоянных сотрудников, примерно столько же временных (почасовых) работников, есть волонтеры. Их практики взаимодействия выстраиваются исходя из общего интереса: решать социальную проблему, вместе создавать проект и учиться в процессе, стимулируя рефлексию и расширяя круги взаимопомощи. Мы рассмотрим, как такой способ решения социальных проблем согласуется с контекстом реализации неолиберальной политики, стимулирующей коммерциализацию сферы социального воспроизводства, связанную с заботой о других, поддержанием социальных связей и передачей определенных ценностей.

\section{Исследовательская стратегия и методы}

Исследование в социальном цирке начато по инициативе его сотрудников. Их интересовало, каким образом цирк влияет на участников и, соответственно, в какой мере реализуется заявленная цель: «Менять жизненные сценарии детей и подростков из групп социального риска» (Цирк N 2015). 
Исследование проведено в форме изучения одного случая (кейс-стади), с совмещением качественных и количественных методов. В течение трех лет, начиная с 2014 г., проводились включенные наблюдения на тренировках, спектаклях и публичных дискуссиях, глубинные интервью с сотрудниками цирка (N=9), полубиографические интервью с участниками циркового проекта в возрасте от 9 до 18 лет ( $\mathrm{N}=20)$, а также отслеживались цирковые публикации и журналистские материалы. В 2017 г. проведены формализованные интервью со всеми цирковыми участниками $(\mathrm{N}=42)$ и анкетный опрос среди зрителей $(\mathrm{N}=199)$. В интервью с сотрудниками говорили о миссии и способах ее реализации. В интервью с участниками обсуждали, что нравится в цирковом проекте, приобретенные умения и навыки, их влияние на взаимодействие за пределами цирка. В опросе зрителей выяснялся их состав, ценностные установки, а также готовность поддерживать общественную организацию, занимающуюся раскрытием творческого потенциала детей и подростков.

Исследовательская стратегия исходит из перспективы участников, предполагает выявление способов их взаимодействия между собой и с сотрудниками, а в итоге направлена на анализ того, как через координацию действий создается прецедент включения, при котором расширяются индивидуальные способности и реализуется трансформационный потенциал совместного действия.

\section{Общественные организации в контексте коммерциализации сферы социального воспроизводства}

Развитие общественных организаций происходит в условиях распространения рыночных отношений на ранее не охваченные ими сферы (Dörre 2010). Коммерциализация образования, здравоохранения и социальной защиты ускоряется в процессе реформирования бюджетных организаций, в частности, с принятием в 2010 г. федерального закона № 83-Ф3 о государственных учреждениях. Вместо распределения благ и бюджетные, и автономные организации призваны оказывать социальные услуги. Формирование экономики обслуживания сопровождается развитием не только рыночных или государственных сервисов, но и гражданского сектора: общественных организаций, предоставляющих услуги и демонстрирующих альтернативу прежним государственным институтам (детским домам, досуговым учреждениям). Их деятельность становится предметом государственного регулирования. За время существования социального цирка произошло законодательное оформление деятельности «социально значимых» организаций. Общественные организации становятся поставщиками социальных услуг, классифицируются как «социально ориентированные», «общественно полезные» или «нежелательные». Регламентация ограничивает возможности социальных групп 
мобилизовать ресурсы и заявлять идеологические притязания на гражданство, адресованные как капиталистическим рынкам, так и государству (Лахман 2016: 129).

В исследованиях социальных цирков разных стран развивается дискуссия о направлениях их развития и интерпретации проявившейся тенденции к профессионализации, т.е. формирование профессиональных навыков для обеспечения средств существования. Исследователи расходятся в том, как следует преодолевать исключение: меняя индивида (Spiegel et al. 2019) или среду (Sorzano 2018). Франко-канадские исследовательницы пришли к выводу, что включение участников происходит за счет существенной личной трансформации: повышения желания продолжить школьное образование, появления карьерных устремлений (Spiegel et al. 2019). С такой установкой «глобального севера» определять социальный цирк лишь как инструмент социальной работы не согласна исследовательница цирковых проектов из Колумбии. Она критикует гегемониальный дискурс, навязываемый «глобальному югу», где профессиональное цирковое обучение сочетается с эмансипационной борьбой за изменение общества и главное - за другой подход к участникам: не как к благополучателям, а как к артистам (Sorzano 2018).

В этой связи ученые по-разному оценивают и процессы профессионализации социальных цирков. Канадские исследователи характеризуют их в качестве новой производственной логики, обозначающей уход от социальной работы, ориентацию на профессиональные выступления и появление проблемы неоплачиваемого труда выступающих участников (Spiegel et al. 2019). Они критически оценивают эту тенденцию, связывая ее со сворачиванием социальной работы с маргиналами. Латиноамериканские исследователи (Sorzano 2018), напротив, полагают, что профессионализация coциально-ориентированных цирковых проектов усиливает маргиналов и таким образом способствует социальной трансформации. С резкой критикой возможности включения и социальной трансформации с помощью циркового искусства выступают исследователи бразильских социальных цирков. Они считают, что социальный цирк как филантропический вид искусства в союзе с неолиберальным государством не искореняет социальное неравенство, а напротив, дисциплинирует бедных. Участники цирковых проектов не получают профессионального образования и только единицы могут рассчитывать на рабочее место в цирке (Lobo, Cassoli 2006).

Мы же утверждаем, что профессионализация в социально-ориентированных общественных организациях может менять систему лишь при условии повышения способности маргиналов действовать и лично управлять жизненной ситуацией. В этой связи мы считаем продуктивной реконструкцию концепции включения через изучение механизмов, соединяющих индивидуальный и системный уровни эмансипационных социальных изменений. 


\section{Теоретическая загадка: \\ концепция «включения» для новой солидарности}

Мы предпочитаем рассматривать «включение» как процесс разворачивания потенциала, когда с реализацией внешних возможностей происходит накопление внутренних ресурсов, а также повышается способность действовать и производить позитивный эффект. Концептуальные рамки исследования формировались на соединении возможностного подхода, феминистской теории онтологии социального и социологического марксизма.

Возможностный подход (capability approach) - расширение возможностей самостоятельно управлять личной жизненной ситуацией, способность к значимому действию (Сен 2004). Он фокусируется на структурах возможностей и на процессе производства социальной позиции через взаимодействие индивида и общества. Обладает эвристическим потенциалом для развития социологической теории действия через совмещение ресурсного понимания деятеля (agency) с представлениями о хорошем обществе и для объяснения действия, обладающего нормативным преимуществом (Gangas 2016). Однако этот подход слабо учитывает социальную составляющую и то, как действуют механизмы власти. Поэтому перспективно дополнить его теорией об онтологии социального, проявляющегося в координации действий в конкретном месте (Smith 2005; МсСоу 2006). Иными словами, с помощью исследователя можно раскрыть управляющие отношения, ограничивающие автономию и способность менять жизненную ситуацию. Задача социолога-стремиться к приращению работающего знания и содействовать раскрытию того, как действия внутри конкретной ситуации координируются извне. При таком понимании становится яснее, что происходит в конкретных микроситуациях, но остается туманным, как низовые стратегии вплетаются в институт «включения», а не исключения или подавления, и как можно усилить альтернативу, распространив ее на макроуровень.

Этот недочет можно преодолеть, обратившись к социологическому марксизму, который развивает теорию об освободительной альтернативе капитализму и обращается к реальным утопиям, основанным на использовании действующих социальных институтов капитализма и позволяющим анализировать тезис о том, что эти прикрывающие капитализм с флангов институты сами по себе содержат семена альтернативного общества (Буравой, Райт 2011: 57). Развивать концепцию реальных утопий предлагается исходя из изучения определенных «моральных стандартов», которым альтернативный институт должен соответствовать, и «практического дизайна», то есть имеющихся возможностей их реализации (Wright 2012). Перспективным развитием данной концепции в рамках нашего исследования является анализ процессов солидаризации вокруг гражданского проекта. Отсюда и интерес к новым формам солидарности: рефлексивным, предполагающим не заданные моральные стандарты, а совместное их производство 
и вариативность реализации таким образом, чтобы расширить круги поддержки в обществе и изменить структуры возможностей социально-уязвимой категории, способствуя институциальным преобразованиям.

\section{Вклад участников в производство общего смысла: атмосферное место}

Участники циркового проекта-дети и подростки со сложной жизненной ситуацией- старались обойти разговоры о неблагополучии или трудностях, с которыми они сталкивались в жизни. Чувствительная тема об отношениях с родителями, сверстниками в школе и окружающими проявлялась в кратких замечаниях. Не нравится, что школу, в которой учатся, называют «бомжастой», что родителей представляют в невыгодном свете, что сталкиваются с жестокостью и агрессией со стороны одноклассников.

На этом фоне цирк, по их мнению, отличается особой атмосферой: дружественной, «офигенной» и доброй. В целом «атмосферность» важна для участников, отмечается ими как нечто привлекательное и значимое. В более развернутом виде привлекательные стороны цирка и его характеристики в качестве атмосферного места представлены в данных формализованных интервью $(\mathrm{N}=42)$ в ответах на открытый вопрос «Социальный циирк-это...». Мы закодировали широкий перечень черт, приписываемых цирку, и сгруппировали их исходя из преобладающей логики ориентаций. Одни характеристики связаны с представлением о цирке как доме и семье, команде, друзьях и в целом добрых людях $(\mathrm{N}=15)$. Другие касались представлений о цирке как особом месте, где можно реализовать свои мечты $(\mathrm{N}=12)$. Третьи обозначали цирк через занятия: связанные с пользой $(\mathrm{N}=6)$, с творчеством $(\mathrm{N}=3)$ или с перевоплощением $(\mathrm{N}=6)$, т. е. с возможностями изменения и повышения статуса. На этом основании в дальнейшем мы уточнили аналитические категории, характеризующие разные уровни включения: к другим, к миру и к себе. Примечательно, что девочки чаще мальчиков приписывают цирку «атмосферность», однако мальчики с выраженным опытом лишений, также рассуждают об особой атмосфере в цирке. Среди подростков из рабочей среды цирк как атмосферное место скорее ассоциируется с другим миром, нежели только с семьей или вторым домом, как у подростков из семей специалистов и служащих. Они скорее связывают цирк с перевоплощением, тогда как для сверстников из семей с более высоким статусом цирк является полезным занятием.

Таким образом, в представлениях участников цирк характеризуется с трех сторон: как особая организация социальных отношений (дружественных), как альтернативное место (где реализуются мечты) и как способ мобилизации или накопления внутренних ресурсов (через перевоплощение, полезное занятие или творчество). Далее через призму участников рассмотрим, как сотрудники представляют эти три составляющие социального цирка. 
Если для участников цирк-это в первую очередь дружественное место, то сотрудники описывают отношения в нем как уважительные и гуманистически окрашенные:

Но у меня такое ощущение, что цирк дает такой инструментарий ребятам и показывает, как можно нормально, на основе гуманистических ценностей сосуществовать <.. > Соответственно, у них появляются какие-то мечты и стремления» (Администратор).

Для участников цирковое пространство- это альтернатива, а среди сотрудников оно скорее ассоциируется с отдельным миром, который занимает свободное время участников:

Получается, что мы вокруг ребят немножко создаем такую искусственную среду, такую вакуумную <.. > И я его искусственно из этой [другой] среды вытаскиваю. И через какое-то время у него у самого уже нету желания, интереса в нее возвращаться (Социальный работник).

Наконец, если участники рассматривают цирк в качестве средства для перевоплощения, то сотрудники представляют цирковой метод как основание для развития творческого потенциала. Во-первых, под этим понимается осознание внутренних возможностей, когда участники, со слов художественного руководителя, «обращаются к своему внутреннему состоянию, прислушиваются к нему» и готовы оценить свои личные качества, осознать, что они хотят и как это можно реализовывать. Во-вторых, при этом важно научиться выражать себя и развивать самовыражение через культурное (заметное и признаваемое во вне) действие. Это как «субкультурный» пропуск в другой мир. В-третьих, осмысление себя дополняется готовностью делать личный выбор или, по крайней мере, противостоять жизненным трудностям и неблагополучной социальной среде. Возможно поэтому так близка сотрудникам идея раскрытия «творческого потенциaла», который понимается как некая сопротивляемость жизненным невзгодами, готовность и способность их преодолевать (Руководитель проекта). И несмотря на то что ситуация в родительских семьях не меняется (об этом и меньше всего рассуждений сотрудников), считается, что «появляется выбор: не у всех, но у многих есть. За счет того, что они на улице проводили мало времени, они в эту среду асоциальную, как например, их одноклассники, не попали» (Социальный работник), т. е. появляется выбор между дворовой или цирковой компанией.

Между тем выбор в пользу цирка дается с трудом и далеко не всем: из 30 набранных участников спустя год остается половина, а до выпуска доходит только треть. Иными словами, цирковой проект не может решить всех проблем, с которыми сталкиваются дети из социально-уязвимых семей. Это показывает как возможности, так и пределы конструирования другой реальности через усиление индивида. Сами участники в первую 
очередь ценят, что в их жизни появляется «атмосферное» место с дружественным к ним отношением, а сотрудники-цирковой метод, усиливающий детей таким образом, что они могут лично влиять на жизненные ситуации и самостоятельно преодолевать неблагополучие. В представлениях об особых социальных отношениях и участников, и сотрудников не хватает согласованности: они расходятся в том, что дети готовы включаться в другой мир и другие отношения через конкретные действия и прагматичный выбор, а сотрудники сосредоточены на изменении ценностей и моральном выборе. Одним из вариантов достижения согласия могло бы быть диалоговое общение- «Вовлечение в процесс критической рефлексии как педагогов, так и учеников, где возникает прецедент взаимной гуманизации» (Freire, Ramos 2009: 166). Тогда атмосферное место может стать местом для практических изменений, а вместо активизации индивида, к чему склоняются сотрудники цирка, вместе с осознанием контекста, может произойти осознание причин угнетения (Фрейре [1970] 2018). Однако практика показывает, что это трудоемкий и длительный способ преобразования социального порядка и перестройки базовых структур, порождающих неравенство. Рассмотрим далее траектории включения участников в цирк и то, как они вписываются в их жизненный мир.

\section{Практики взаимодействия в цирке: траектории включения}

В полубиографических интервью (N=20) после вводного вопроса: «Что с тобой произошло с тех пор, как ты попал/а в цирк?», участники циркового проекта рассказывают о разных траекториях включения с помощью циркового проекта. Данные траектории раскрываются через призму аналитических категорий включения к себе и включения к миру, а также варьируются в зависимости от наличия или отсутствия уличного опыта.

Первую траекторию через изменение отношения к себе мы назвали перевоплощением. При ее описании молодые артисты раскрывают свое включение в цирк через позиционирование к понятию «хулиган»: «Многое изменилось. Во-первых, характер. Я раньше был гопником. Хулиганил очень много, ОЧЕНЬ много. Гулял всё время» (м., 16 лет). Мальчик в ходе интервью описывает, как постепенно превращался из уличного «гопника» в циркового артиста, дистанцируясь от прежнего жизненного мира. Такое восприятие характерно для участников с уличным опытом и концептуально вписывается в идею проекта «изменить жизненный сценарий». При этом артисты, не познавшие «улицу», пользуются другой интерпретацией:

Цирк для хулиганов- это не для хулиганов таких, которые курят или пьют. Это для таких, которые могут сделать очень, очень все круто. <..> Есть такой человек, который построил [цирк]. Вот он крутой. $<\ldots>$ Которые могут что-то сделать, главное, что-то открыть (ж., 16 лет). 
В вышеприведенной цитате девочка дистанцируется от уличных хулиганов, приписывая им злоупотребление наркотическими средствами. Она конструирует «позитивного» хулигана с качествами «крутого новатора». Эта коннотация является общей среди тех, кто не считает себя уличным и пытается найти для себя прототип «позитивного» хулигана, при этом даже повторяя стигматизирующие качества «уличных» хулиганов. Такая траектория включения характеризуется вживанием в образ. При этом обнаруживается противоречие между попыткой повысить социальный статус «уличных» хулиганов, и их отвержением и дальнейшей стигматизации в глазах участников без уличного опыта. Однако установка цирка на «уличных» хулиганов считывается всеми участниками. Они сходятся в том, что считают себя «цирковыми» хулиганами, некоторым из них приходится перевоплощаться, а другим найти в себе какое-то необидное хулиганское начало.

Юные артисты проясняют, как их «борьба» за признание для включения в цирк связана с участием в спектаклях, в которых проигрывание ролей может как совпадать, так и расходиться с их жизненным опытом и их энергией. В следующей цитате жизненный опыт участника и цирковая роль совпадают: «Я не знаю, как она [режиссер] угадывает всё время, что мне идёт больше эта роль. Я влился легко в моряка. Этот моряк у нас-как почти хулиган, только он немножко деликатней и такой серьёзныйџ (м., 16 лет). Этот мальчик играет ту роль, которая под него придумывалась и которую он живо, как будто играя самого себя, легко может воплощать на сцене. Таким образом он подчеркивает близость его цирковой роли и собственного «хулиганского» опыта, что облегчает ее исполнение. В следующей истории участницы без хулиганской энергии отмечается расхождение жизненного опыта и цирковой роли: «Играла сначала Мила, потом начала играть я. Я сначала не понимала, кого я играю. Мне было не понятно» (ж., 16 лет). Девочка отмечает сложность вхождения в свою роль, которая не соответствует ее опыту. В итоге участникам с хулиганским опытом облегчена задача воплощения в роль, тогда как участникам без хулиганского опыта приходится вживаться в образ.

Две другие траектории характеризуют включение к миру. Участники с хулиганским опытом представляют его как соревновательную борьбу за признание: «Вот там есть ребята, которые в том году что-то добились, а сейчас это не продолжается, и у них это так и осталось. <...> А я вот пытаюсь за каждый месяц там что-то новое, новое, новое- продолжать. Вот этим я и горжусь» (м., 16 лет). Этот мальчик готов трудиться, постоянно осваивать новое в цирковом мастерстве и- главное- видит в этом повод для гордости. Такую траекторию включения можно считать конкурентно-ориентированной, поскольку она формируется в борьбе участников за «лучшее» техничное исполнение цирковых трюков.

В отличие от мальчиков у девочек нет рассказов про уличный опыт: «[уйти из циика] хотела, очень, потому что мне не очень нравилось. Там 
была сначала акробатика, которая мне вот не очень давалась. И потом я нашла свое преимущество: воздушную акробатику» (ж., 16 лет). Этой девочке не нравились занятия темповой акробатикой, к тому же они у нее не получались. Она включилась в цирк, заняв подходящую ей нишу. Ее рассказ типичен для девочек и мальчиков без «уличного» опыта. Они описывают свою форму включения в цирк как поиск своего особого места, своей ниши. При этом конкуренция между участниками цирка из более благополучной среды и теми, кто имеет уличный опыт, неравная:

Начался набор в спектакль. $<\ldots>$ И было три мальчика $<\ldots .>$ Они сначала нормально играли, а потом $\mathrm{K}^{*}$, он просто не стал приходить на тренировки. И когда он пришёл, ему сказали: «Ну, у нас просто уже спектакль готов, а ты ничего не умеешь, так что мы тебя не берём». Другой мальчик сказал, что он не хочет уезжать, потому что у него мама болела. А другой, он просто был расслабленный (ж., 11 лет).

Эта девочка тренировалась в цирке, пока ее конкуренты по разным причинам выпадали из процесса подготовки спектакля, поэтому она и получила роль. Такая возможность включения через регулярное посещение занятий наблюдается у детей из семей специалистов и служащих. Мальчик, который часто прогуливал цирковые репетиции и выступления из-за своих социальных проблем рассказывает: «Когда [снова] пошёл, они думали, что я опять, типа, загуляю, все дела. А я не загуливал, ничего, ходил, думал, возьмут. Они говорят: "Ну типа, мы тебя не можем взять [в спектакль], потому что ты можешь нас подставить"» (м., 17 лет). Его пропуски наказываются недоверием, снижением статуса и моральным осуждением. Из его перспективы очевидно то, как трудно снова включаться, полагаясь только на личный выбор.

При исполнении спектаклей виден тонкий подход к уязвимым или «особенным» детям через максимальную поддержку уникальных талантов каждого и взаимовыручки. В цирковом быту эта взаимовыручка детей разных групп и полов осложнена профессионализацией, т. е. установкой цирка на достижение, которая может быть скорректирована формированием социальных навыков по согласованию разных позиций.

\section{Практики взаимодействия вне цирка: рефлексивная солидарность}

Основной акцент в работе с подростками делается на воспитании и создании прецедента для использования цирковой культуры в качестве ресурса или средства для реализации возможностей вне цирка. При этом упор делается не только на изменение участников, но и на создание правил и инструментов, позволяющих им самим «разворачивать культурный код», выстраивая отношения с окружающими. Участники циркового проекта развивают эту идею, фиксируя происходящие с ними изменения и описывая приобретаемые навыки. 
Для выходцев из рабочей среды значимо появление целеполагания и упорства: «На самом деле циирк мне помог понять, что в жизни важно. Он мне дал, можно сказать, цуель» (ж., 16 лет). Для детей из семей специалистов и служащих лейтмотивом проходит тема принятия самих себя, осознания своей идентичности: «У меня вместе с цииком очень изменился характер: до цирка у меня был такой нервный, очень нервный характер, то есть агрессивный. А в изирке я стала более спокойной» (ж., 18 лет). $\mathrm{B}$ то же время подростки подчеркивают, что им важно окружение и они учатся взаимодействовать друг с другом. Согласно данным формализованных интервью, приоритетное значение для детей и подростков, независимо от классовой принадлежности, имеют все-таки социальные навыки: появление друзей, знакомство с теми, кто играет положительную роль в их жизни или на кого они хотят быть похожи. Не удивительно, что практически все, с кем мы разговаривали, подчеркивали, что в цирке они приобретают друзей, что с течением времени дворовые компании или сверстники в школе отходят на второй план. С цирковыми друзьями ходят в кино, выезжают на природу или посещают батутные клубы. Даже после выпуска или ухода из цирка остаются приятельские отношения с участниками циркового проекта.

Надо отметить, что уход из цирка по возрасту воспринимается как вынужденный. Они настолько погружаются в цирковой проект, что начинают связывать с ним свои дальнейшие жизненные планы. Становится важным продолжение профессиональной карьеры, связанной с цирком (быть артистом или педагогом). Среди участников есть примеры поступления в педагогический колледж, цирковое училище, несколько человек работают тренерами в городских досуговых центрах. Можно сказать, что некоторым участникам таким образом удается изменить жизненный сценарий и превзойти неблагополучную родительскую позицию. Однако следует признать, что дается это далеко не всем и большими усилиями, в частности, преодолением фильтров образования для детей из коррекционных школ.

Между тем, у цирка есть сторонники и об их составе свидетельствуют данные опроса зрителей, регулярно посещающих спектакли социального цирка: большую их часть составляют женщины (75\%), люди с высшим образованием (80\%), а также работающие в так называемых отраслях социального воспроизводства (61\%), то есть в культуре, образовании, в различных общественных организациях, а также занятые в сфере обслуживания (22\%). Следует подчеркнуть, что примерно треть опрошенных отметили, что непосредственно связаны с участниками циркового проекта: являются родителями, родственниками, друзьями и знакомыми участников циркового проекта. Иными словами, целевая аудитория и круг поддерживающих цирковой проект смешаны по классовому составу, хотя большую часть составляет образованный класс. Высока доля тех зрителей, 
кто разделяет идеологию общественной организации. Так, около половины отметили, что цирк раскрывает в них творческий потенциал и еще примерно треть скорее согласны с этим. Еще больше, около $90 \%$ из тех, кто уже бывал в цирке, уверены, что творческими методами можно изменить жизненный сценарий детей и подростков из групп социального риска.

По мнению сотрудников цирка, для этого требуется создание сети культурных и социальных институтов или создание «системы», сопровождающей процесс «разворачивания культурного кода» творческими методами. Подготовка спектакля становится творческой лабораторией, в которой помимо режиссера, тренеров и артистов, принимают участие музыканты, художники, мультипликаторы и другие профессионалы. Успешность постановок связывается с совместной работой, с нацеленностью на результат и признание со стороны зрителей. Однако социальный работник считает, что при этом надо сопровождать детей: «Первичным все-таки является решение сочиальных вопросов, связанных с родителями, со школой, с документами, с успеваемостью, с психиатрическими лечебницами, с детдомами». Иными словами, действия социального работника направлены на то, чтобы ничто не мешало ребенку посещать цирк. В своей деятельности она сотрудничает с работниками разных общественных организаций и стремится согласовать действия с другими инстанциями, сопровождающими детей в сложной ситуации. Тем не менее у социального цирка приоритетной является позиция не систематического сопровождения семьи ребенка, а усиление подростка, развивающее индивидуальный потенциал и обеспечивающее внешнее признание.

Производство спектаклей является важной составляющей совместной деятельности сотрудников и участников социального цирка, источником примерно четвертой части доходов организации. Более того, около 80 \% зрителей выразили готовность помогать, а треть-уже помогали в разных формах. С принятием в 2012 г. закона «Об иностранных агентах» зарубежное финансирование сократилось. Примечательно, что на этом фоне и государственное финансирование снизилось с 9\% в 2016 г. до $2 \%$ в 2017 г. Руководительница одного из проектов отметила, что для получения государственной поддержки заложены количественные показатели, т.е. важна массовость. Отбираются проекты, продвигающие патриотическое или православное воспитание. Этим критериям социальный цирк не соответствует: «Mы не массовые... Хотим остаться со своим лицом, не хотим выполнять такой заказ». По ее мнению, государству не нужны новаторы. Недоверие к государству контрастирует с признанием достоинств скандинавской системы, где государство и городской бюджет оплачивают расходы похожего циркового проекта. Вместо отстаивания права на государственную поддержку успешного проекта, сотрудники сосредоточены на привлечении средств благотворителей и развитии коммерческой составляющей. 


\section{Заключение}

Во время исследования мы анализировали собранные в ходе кейсстади данные таким образом, чтобы выявить существующий в цирке модус включения: как представляется социальный цирк разными сторонами, какие действия предпринимают участники для включения в него и как цирковые достижения отражаются на взаимодействии за его пределами. На каждом направлении проявляются перспективы и пределы включения - расширение индивидуального потенциала и изменения структуры возможностей творческими методами.

В производстве общего смысла возникает противоречие между тем, что привлекает в цирковом проекте разных участников. Детям в социальном цирке в первую очередь нравятся отношения, а затем-альтернативное место, где они могут цирковыми средствами повысить способность лично влиять на жизненные ситуации. При этом участники из семей рабочих признают значимость личной трансформации (перевоплощение, а не исключительно дисциплинирование), а дети из семей специалистов и служащих - полезное занятие. Однако интересы участников недооцениваются, и сотрудникам организации следует научиться выстраивать диалоговое общение таким образом, чтобы принять во внимание их перспективу.

Включение происходит за счет работы по изменению статуса «хулиганов»: у ребят с хулиганским опытом это реализуется через воплощение их жизненного опыта на сцене и борьбу за признание, а у тех, кто без хулиганского опыта-через вживание в роль и занятие своей ниши. В ходе тренировок и постановок спектаклей установка на результат и творческий подход в его достижении становятся ресурсом для личной трансформации. Однако для всех детей важно не только осознание своих целей, но и приобретение навыков общения и социальных ресурсов. Чтобы стратегии включения меняли структуры возможностей, надо встать на позицию «настоящих хулиганов» (маргиналов) и понять, как избежать их повторной стигматизации, а также развивать навыки по согласованию разных позиций.

Общественная организация стремится повысить статус детей и подростков из групп социального риска, привлекая к ним внимание. Ее деятельность находит отклик и поддержку среди подобных организаций, получает признание со стороны профессионального сообщества, занятого в сфере заботы, находит спонсоров и самостоятельно развивает коммерческое направление. Организация стремится сохранить самодостаточность, отстаивая свои интересы в кооперации как с бизнес-структурами, так и с государством. Она привлекает внимание к проблемам детей из бедных семей, становится промежуточным звеном между рынком и государством, вносящим вклад в институциальные преобразования. Однако окончательный результат зависит от понимания условий, ведущих к неблагополучию. 


\section{Список источников}

Буравой М., Райт Э. О. (2011) Социологический марксизм. Социология. (2): 43-57.

Лахман Р. (2016) Что такое историческая соичология? М.: Дело.

Лыткина Т. С. (2012) Социальный капитал в решении социальных проблем: практики солидарности бедных в Республике Коми. Журнал сочиологии и соииальной антропологии, XV (3): 130-154.

Сен А. (2004) Развитие как свобода. М.: Новое издательство.

Фрейре П. (2018) Педагогика угнетенных. М.: КоЛибри.

Цирк N (2015) Метод циика N. СПб: Цирк N.

Burawoy M. (2015) Facing an Unequal World. Current Sociology, 63 (1): 5-34.

Dörre K. (2010) Social Classes in the Process of Capitalist Landnahme. On the Relevance of Secondary Exploitation. Socialist Studies/Études socialistes, 6 (2): 43-74.

Fraser N., Honneth A. (2003) Redistribution or Recognition? A Political-philosophical Exchange. London: Verso.

Freire P., Ramos M. B. (2009) Pedagogy of the Oppressed. Race/Ethnicity: Multidisciplinary Global Contexts, 2 (2): 163-174.

Gangas S. (2016) From Agency to Capabilities: Sen and Sociological Theory. Current Sociology, 64 (1): 22-40.

Kerner I. (2017) Relations of Difference: Power and Inequality in Intersectional and Postcolonial Feminist Theories. Current Sociology Review, 65 (6): 846-866.

Lobo L., Cassoli T. (2006) Circo Sociale prácticas educacionais nao governamentais. Psicologia \& Sociedade, 18 (3): 62-67.

McCoy L. (2006) Keeping the Institution in View: Working with Interview Accounts of Everyday Experience. In: D. Smith (ed.) Institutional Ethnography as Practice. Oxford: Rowman \& Littlefield: 109-125.

Paret M., Runciman C., Sinwell L. (eds.) (2017) Southern Resistance in Critical Perspective: The Politics of Protest in South Africa's Contentious Democracy. London: Routledge.

Smith D. E. (2005) Institutional Ethnography: A Sociology for People. Toronto: AltaMira Press.

Sorzano O. (2018) Is Social Circus 'The Other' of Professional Circus? Performance Matters, 4 (1-2): 116-133.

Spiegel B. J., Ortiz Choukroun B., Campaña A., Boydell K. M., Breilh J., Yassi A. (2019) Social Transformation, Collective Health and Community-Based Arts: 'Buen Vivir' and Ecuador's Social Circus Programme. Global Public Health, 14 (6-7): 899-922.

World Bank (2013) Inclusion Matters: The Foundation for Shared Prosperity. Washington: International Bank for Reconstruction and Development.

Wright E. O. (2012) Transforming Capitalism Through Real Utopias. American Sociological Review, XX (X): 1-25. 


\section{THE SOCIAL CIRCUS IN POST-SOCIALIST RUSSIA: A CASE STUDY OF NEW SOLIDARITY}

This article is based on a case study of the Social Circus, a Russian NGO created in the 2000s that focuses on developing the potential of children from social risk groups. We analyse how the inclusion of these children into society is performed, how the circus's methods and socially oriented activism manage to solve the problem of exclusion and reproduction of poverty in Russia. We analysed the subjective meanings attributed to the social circus by participants, civic activists and supporters; then we explored internal strategies of inclusion into the circus elaborated by participants from different social classes and how these strategies were supported by different external parties. In this way, we were able to reconstruct the concept of inclusion and present it as a process of realization of capabilities, when, with the realization of external opportunities, the accumulation of internal resources takes place, as well as the ability to act and produce a positive effect. We argue that the inclusion of socially disadvantaged groups can change the structure of opportunities in practice under three conditions. Firstly, through a change in the status of socially disadvantaged groups, when negative identification forms a platform for the practical promotion of the special status and differences of participants, considering their interests. Secondly, attitudes towards achievement strengthens the positions of participants, if it is combined with the formation of social skills to coordinate different positions. Thirdly, opportunities are accumulated if they are fixed in emancipation methods of interaction at the individual, group and local levels, involving the recognition of the causes of oppression, the promotion of the interests of disadvantaged groups, the reformatting of their experience and the accumulation of social ties. As a result, reflective solidarity is considered, involving the joint development of moral guidelines and the variability of their implementation.

Key words: social circus, case-study, regime of inclusion, ruling relations, sociological Marxism, post-socialism

DOI: 10.17323/727-0634-2020-18-3-491-508

\section{References}

Burawoy M. (2015) Facing an Unequal World. Current Sociology, 63 (1): 5-34.

Svetlana Yaroshenko - Cand. Sci. (Soc.), docent in comparative sociology, St. Petersburg State University, St. Petersburg, Russian Federation. Email: s.yaroshenko@ spbu.ru

Astrid Schorn- Doctoral Student, Free University, Berlin, Germany. Email: astrid.schorn@ fu-berlin.de 
Burawoy M., Wright E. O. (2011) Sociological Marxism. Sotsiologiya [Sociology], (2):43-57.

Dörre K. (2010) Social Classes in the Process of Capitalist Landnahme. On the Relevance of Secondary Exploitation. Socialist Studies/Études socialistes, 6 (2): 43-74.

Fraser N., Honneth A. (2003) Redistribution or Recognition? A Political-philosophical Exchange. London: Verso.

Freire P. (2018) Pedagogika ugnetennykh [Pedagogy of the Oppressed]. Moscow: KoLibri.

Freire P., Ramos M.B. (2009) Pedagogy of the Oppressed. Race/Ethnicity: Multidisciplinary Global Contexts, 2 (2): 163-174.

Gangas S. (2016) From Agency to Capabilities: Sen and Sociological Theory. Current Sociology, 64 (1): 22-40.

Kerner I. (2017) Relations of Difference: Power and Inequality in Intersectional and Postcolonial Feminist Theories. Current Sociology Review, 65 (6): 846-866.

Lachmann R. (2016) Chto takoe istoricheskaya sotsiologiya? [What is Historical Sociology?]. Moscow: Delo.

Lobo L., Cassoli T. (2006) Circo Sociale prácticas educacionais nao governamentais. Psicologia \& Sociedade, 18 (3): 62-67.

Lytkina T. (2012) Sotsial'nyy kapital v reshenii sotsial'nykh problem: praktiki solidarnosti bednykh v Respublike Komi [Social Capital in Solving Social Problems: Practices of Solidarity of the Poor in the Komi Republic]. Zhurnal sotsiologii i sotsial'noj antropologii [Journal of Sociology and Social Anthropology], XV (3): 130-154.

McCoy L. (2006) Keeping the Institution in View: Working with Interview Accounts of Everyday Experience. In: D. Smith (ed.) Institutional Ethnography as Practice. Oxford: Rowman \& Littlefield publishers: 109-125.

Paret M., Runciman C., Sinwell L. (eds.) (2017) Southern Resistance in Critical Perspective: The Politics of Protest in South Africa's Contentious Democracy. London: Routledge.

Sen A. (2004) Razvitie kak svoboda [Development as Freedom]. Moscow: Novoye izdatelstvo.

Smith D. E. (2005) Institutional Ethnography: A Sociology for People. Toronto: AltaMira Press.

Sorzano O. (2018) Is Social Circus ‘The Other' of Professional Circus? Performance Matters, 4 (1-2): 116-133.

Spiegel B. J., Ortiz Choukroun B., Campaña A., Boydell K. M., Breilh J., Yassi A. (2019) Social Transformation, Collective Health and Community-Based Arts: 'Buen Vivir' and Ecuador's Social Circus Programme. Global Public Health: 14 (6-7): 899-922. 
Tsirk N (2015) Metod tsirka N [Method of Circus N]. St. Petersburg: Tsirk N.

World Bank (2013) Inclusion Matters: The Foundation for Shared Prosperity. Washington: International Bank for Reconstruction and Development.

Wright E. O. (2012) Transforming Capitalism Through Real Utopias. American Sociological Review, XX (X): 1-25. 